\title{
Comparative analysis of the various structures quinoline derivatives retention under RP HPLC
}

\author{
(C) Andrey Yu. Kholin, ${ }^{1}$ Svetlana V. Kurbatova, ${ }^{1}{ }^{+}$and Margarita N. Zemtsova ${ }^{2}$ \\ ${ }^{1}$ Department of Physical Chemistry and Chromatography. Samara National Research University. \\ Acad.Pavlova St., 1. Samara, 443011.Russia.E-mail: curbatsv@gmail.com \\ ${ }^{2}$ Samara State Technical University. St. Kuibyshev, 153. Samara, 443010. Russia. Fax: +7 (846) 332-21-22
}

\author{
*Supervising author; ${ }^{+}$Corresponding author
} Keywords: quinoline derivatives, reversed phase high performance liquid chromatography, octadecyl silica gel, influence of molecular structure and physicochemical parameters on retention.

\begin{abstract}
The study results of the structure and physicochemical parameters effect of various quinoline derivatives on their retention under conditions of reversed-phase high-performance liquid chromatography are presented. It is shown that since the establishment of the relationship between the structure of a substance and its properties is still one of the most important problems of modern chemistry and materials science, chromatography is a very convenient and effective method for obtaining the information necessary for this. To establish the relationship between the structure and sorption characteristics of substances, on the one hand, the parameters of the electronic structure of sorbate molecules, their hydrophobic properties, quantum-chemical, topological and other physicochemical characteristics of organic compounds are used, as well as various computer programs and computer modeling methods that make it possible to analyze and to compare the numerous data on the chromatographic retention of compounds of various chemical nature, on the other. At the same time, for the final conclusions about the possibility of using the obtained dependences and correlations for assessing and predicting the properties of new compounds, a significant sample of compounds of various compositions is required, with the use of which the corresponding "structure - property" relationships are obtained.

By now, reference books and computer databases on the chromatographic retention of organic compounds are known, containing information on a fairly large number of objects. However, these databases usually contain information predominantly about the retention of compounds under gas chromatography conditions. There are practically no corresponding libraries and databases for liquid chromatography, which is primarily due to the variety of liquid chromatographic systems differing both in the nature and composition of stationary phases and eluents, and in the chromatographic conditions. For the conditions of liquid chromatography, the possibility of using such schemes is complicated by the existence of a large number of interactions in the chromatographic system, due, first of all, to the presence of an active eluent.

It is shown in this work that heterocyclic compounds are suitable models for these purposes, a feature of which is the possibility of modifying their properties by varying the structure within wide limits. In this work, the influence of the presence of heteroatoms, a change in the position of the same heteroatom in the main heterocyclic fragment, and the presence of functional groups and substituents of various natures on chromatographic retention under RP HPLC conditions were studied.
\end{abstract}

\section{References}

[1] T. Le, V.C. Epa, F.R. Burden. Chem. Rev. 2012. Vol.112. No.5. P.2889-2919.

[2] R. Kaliszan. Chem. Rev. 2007. Vol.107. P.3212-3246.

[3] A.A. Lurie. Chromatographic materials. Moscow: Chemistry. 1978. 440p. (russian)

[4] I.G. Zenkevich, V.I. Babushok, P.J. Linstrom, E. White, S.E. Stein. J. Chromatogr. A. 2009. Vol.1216. P.6651.

[5] NIST/EPA/NIH Mass Spectral Library. Software/Data Version (NIST 05, NIST 08).

[6] V.D. Shatz, O.V. Sakhartova. High performance liquid chromatography. Riga: Zinatne. 1988. 390p.

[7] J.L. Rafferty, L. Zhang, J.I. Siepmann, et al. Anal. Chem. 2007. Vol.79. No.17. P.6551-6558.

[8] N.A. Nekrasova. Sorption of quinoline derivatives and 1,2,3,4-tetrahydroquinoline under RP HPLC. Diss. cand. chem. sci. Saratov. 2018. 134p.

[9] I.N. Karaseva, M.O. Karasev, O.N. Nechaeva, S.V. Kurbatova. J. Phys. Chem. 2018. Vol.92. No. 7. P.11641171. (russian)

[10] L. Fieser, M. Fieser. Organic chemistry. Vol.2. Moscow: Chemistry. 1966. 784p. (russian) 
[11] A.V. Voronkov. High performance liquid chromatography of cinchoninic acid amides and hydrazides. Diss. cand. chem. sci. Moscow. 2005. 163p. (russian)

[12] A.S. Savchenkova. Physicochemical regularities of the sorption of quinoline derivatives from aqueous acetonitrile solutions under RP HPLC. Diss. cand. chem. sci. Saratov. 2016. 121p. (russian) 